\title{
UPAYA PENINGKATAN PENGETAHUAN IBU HAMIL TENTANG TANDA BAHAYA KEHAMILAN DALAM MENGHADAPI PROSES PERSALINAN YANG AMAN
}

\section{Efforts To Improve The Knowledge Of Pregnant Women About The Dangers Of Pregnancy In Facing Safe Labor Processes}

\author{
Ririn Handayani ${ }^{1}$ \\ Program Studi S1 Kebidanan STIKES dr.Soebandi Jember ${ }^{1}$ \\ Email : zahraaina12gmail.com
}

\begin{abstract}
ABSTRAK
Upaya penurunan AKI membutuhkan aksi pada beragam level. Selain posyandu, kelas ibu hamil juga dianggap sebagai kelas yang paling efektif untuk meningkatkan pengetahuan ibu hamil dalam mengenali risiko dan tanda bahaya selama masa kehamilan serta sebagai sarana penting untuk merubah sikap dan perilaku ibu hamil. Dengan adanya kelas ibu hamil ini diharapkan seluruh ibu hamil dapat memiliki kemampuan melakukan deteksi dini tanda bahaya kehamilan sehingga ibu hamil dapat dengan nyaman melakukan proses persalinan tanpa ada kekhawatiran terhadap proses persalinan yang dihadapi dan secara tidak langsung dapat menurunkan angka kematian ibu. Salah satu faktor resiko yang juga menyumbang tingginya angka kematian ibu adalah persalinan yang ditolong oleh dukun dan ibu hamil dengan resiko tinggi. Hasil wawancara dengan bidan penanggung jawab di Desa Suco didapatkan informasi bahwa dalam satu tahun terahir terdapat ibu hamil yang melahirkan didukun tanpa pengawasan oleh tenaga kesehatan atau bidan. Beberapa ibu cenderung menarik diri dari petugas kesehatan dikarenakan faktor sosial ekonomi dan ketidaktahuan dari ibu hamil tentang tanda bahaya pada kehamilan dan saat proses persalinan. Desa Suco ini merupakan desa yang berada di wilayah kerja Puskesmas Mumbulsari Kabupaten Jember. Kelas ibu hamil merupakan kelompok khusus ibu hamil yang rutin diselenggarakan di Desa Suco. Melalui kegiatan tersebut, peneliti ingin memberikan pendidikan kesehatan kepada masyarakat khususnya ibu hamil tentang deteksi dini tanda bahaya dalam kehamilan dalam rangka persiapan proses persalinan yang aman dan sebagai upaya untuk menurunkan angka kematian ibu.
\end{abstract}

Kata kunci : Tanda bahaya kehamilan, Kehamilan resiko tinggi

\section{ABSTRACT}

Efforts to reduce AKI require action at various levels. Aside from posyandu, the class of pregnant women is also considered as the most effective class to increase the knowledge of pregnant women in recognizing risks and danger signs during pregnancy as well as an important means of changing attitudes and behavior of pregnant women. With this class of pregnant women, it is expected that all pregnant women can have the ability to do early detection of danger signs of pregnancy so that pregnant women can comfortably carry out the labor process without any worries about the labor process they are facing and can indirectly reduce the maternal mortality rate. One of the risk factors that also contributes to the high maternal mortality rate is childbirth which is assisted by not medical personel and pregnant women with high risk. The results of interviews with the midwife in charge in the Suco village obtained information that in the past year there were pregnant women who gave birth to not medical personal without supervision by health workers or midwives. Some mothers tend to withdraw from health workers due to socio economic factors and ignorance of pregnant women about the danger signs during pregnancy and during labor. Suco Village is a village located in the working area of Mumbulsari Public Health Center in Jember Regency. Pregnant women class is a special group of pregnant women routinely held in Suco Village. Through these activities, researchers want to provide health education to the public, especially pregnant women, about the early detection of danger signs in pregnancy in order to prepare for the safe delivery process and as an effort to reduce maternal mortality.

Keywords : Pregnancy danger sign, High risk pregnancy 


\section{PENDAHULUAN}

Angka kematian ibu merupakan keseluruhan atau jumlah perempuan yang meninggal disebabkan oleh karena gangguan selama masa kehamilan atau kesalahan dalam penanganannya selama masa kehamilan, melahirkan dan dalam masa nifas per 100.000 kelahiran hidup. Upaya penurunan AKI membutuhkan aksi pada beragam level, dari tingkat pusat maupun daerah termasuk didalamnya adalah peran serta masyarakat melalui kegiatan posyandu (UNFPA, 2012). Selain posyandu, kelas ibu hamil juga dianggap sebagai kelas yang paling efektif untuk meningkatkan pengetahuan ibu hamil dalam mengenali risiko dan tanda bahaya selama masa kehamilan serta sebagai sarana penting untuk merubah sikap dan perilaku ibu hamil (Tinah, 2010).

Kelas ibu hamil merupakan sarana penting dalam peningkatan pengetahuan dan perubahan perilaku. Dengan adanya kelas ibu hamil diharapkan semua ibu hamil dapat memiliki kemampuan melakukan deteksi dini faktor resiko selama kehamilan sehingga dapat manghadapi proses persalinan yang nyaman dan aman dan secara tidak langsung dapat menurunkan angka kematian ibu.

Faktor resiko dalam kehamilan diantaranya adalah tinggi badan ibu kurang dari $145 \mathrm{~cm}$, usia ibu kurang dari 20 tahun atau lebih dari 35 tahun, telah memiliki anak lebih dari 4, jarak antara kehamilan yang satu dengan yang lain kurang dari 2 tahun, terdapat riwayat proses persalinan yang kurang baik, menderita penyakit yang menyertai kehamilan (anemia, hipertensi, jantung dan sebagainya), mengalami perdarahan, sakit kepala hebat, bengkak pada tungkai, kelainan pada janin (janin besar, malposisi atau malpresentasi), bentuk panggul ibu tidak normal.

Faktor lain yang juga menyumbang tingginya angka kematian ibu adalah persalinan yang ditolong oleh dukun dan ibu hamil dengan resiko tinggi. Hasil wawancara dengan bidan penanggung jawab di Desa Suco didapatkan informasi bahwa dalam satu tahun terahir terdapat ibu hamil yang melahirkan didukun tanpa pengawasan oleh tenaga kesetahan atau bidan. Beberapa ibu cenderung menarik diri dari petugas kesehatan dikarenakan faktor sosial ekonomi dan tingkat pengetahuan yang rendah dari ibu hamil dan keluarga tantang tanda bahaya pada kehamilan dan saat proses persalinan. Proses persalinan dukun telah diketahui banyak menimbulkan komplikasi pada saat proses persalinan. Kemungkinan besar masyarakat di Desa Suco khususnya ibu hamil memiliki pengetahuan yang rendah mengenai tanda bahaya kehamilan sehingga banyak ibu hamil yang melahirkan didukun.

Desa Suco ini merupakan desa yang berada di wilayah kerja Puskesmas Mumbulsari Kabupaten Jember. Kelas ibu hamil merupakan kelompok khusus ibu hamil yang rutin diselenggarakan di Desa Suco. Melalui kegiatan tersebut, peneliti ingin memberikan pendidikan kesehatan kepada masyarakat khususnya ibu hamil tentang deteksi dini tanda bahaya dalam kehamilan dalam rangka persiapan proses persalinan yang aman dan sebagai upaya untuk menurunkan angka kematian ibu.

\section{METODE}

Kegiatan pengabdian masyarakat ini dilaksanakan dengan memberikan penjelasan dan pemahaman tentang tanda bahaya kehamilan melalui media gambar atau poster, PPT dan video. Kegiatan ini dilaksanakan dengan harapan agar agar masyarakat kususnya ibu hamil dapat melakukan deteksi dini adanya kelainan atau komplikasi selama masa kehamilan.

Sasaran pada kegiatan pengabdian masyarakat ini adalah seluruh ibu hamil di Desa Suco wilayah kerja Puskesmas Mumbulsari Kabupaten Jember. Jumlah ibu hamil yang ikut dalam kegiatan pengabdian masyarakat ini sebanyak 29 ibu hamil.

Kegiatan pertama diawali dengan mempersiapkan daftar hadir, berita acara, baner dan kelengkapan lainnya untuk pelaksanaan. Selanjutnya dilakukan perkenalan dan diawali dengan sesi tanya jawab tentang tanda bahaya kehamilan sebelum kegiatan inti dimulai. Setelah sesi tanya jawab, dan memasuki kegiatan inti yaitu memberikan penjelasan tentang tanda bahaya kehamilan dengan menggunakan media leaflet, PPT dan video. 
Diakhir sesi akan dilakukan tanya jawab kembali untuk melihat apakah peserta mampu memahami mengenai materi yang sudah dijelaskan. Selain sesi tanya jawab peserta diminta untuk mengisi lembar kuisioner yang berisi beberapa pertanyaan seputar tanda bahaya kehamilan.

\section{HASIL DAN PEMBAHASAN}

Dari hasil kegiatan ini didapatkan rata rata ibu hamil memiliki pengetahuan yang lebih tinggi diabandingkan sebelum kegiatan pendidikan kesehatan ini dilaksanakan. Hal ini dibuktikan dengan adanya nilai yang didapat dari kuisioner yang telah diisi oleh ibu hamil setelah mendapatkan pendidikan kesehatan tentang tanda bahaya kehamilan. Dari 29 ibu hamil yang telah mengikuti kegiatan ini, $17 \mathrm{ibu}$ hamil $(58,62 \%)$ memiliki pengetahuan yang baik, $10 \mathrm{ibu}$ hamil (34,48\%) memiliki pengetahuan yang cukup dan 2 ibu hamil $(6,89 \%)$ yang memiliki pengetahuan kurang.

Tingkat pengetahuan ibu hamil juga dapat dipengaruhi oleh tingkat pendidikan ibu. Sebagian besar responden berpendidikan SD dan SMP. Dari 29 responden 13 ibu hamil $(44,82 \%)$ berpendidikan SD, 12 ibu hamil (41,37\%) berpendidikan SMP dan 4 ibu hamil $(13,79)$ berpendidikan SMA. Pendidikan meliputi pengajaran keahlian khusus dan juga sesuatu yang tidak dapat dilihat tetapi lebih mendalam yaitu pemberian pengetahuan, pertimbangan dan kebijakan. Sehingga pendidikan dan pengetahuan saling berkaitan. Wanita yang berpendidikan akan membuat keputusan yang benar dalam memperhatikan kesehatan anak-anaknya serta kesehatan dirinya sendiri (Meliono, 2007).

Selain tingkat pendidikan, pengalaman kehamilan terdahulu juga dapat mempengaruhi tingkat pengetahuan ibu tentang tanda bahaya kehamilan dikarenakan ibu sudah pernah medapatkan pendidikan kesehatan pada kehamilan pertama dan ibu sudah pernah mengalami kehamilan sebelumnya sehingga ibu lebih bisa menjaga dan mengerti tentang tanda bahaya kehamilan. Dari 29 responden tersebut ada 13 multipara yang artinya ada 13 ibu hamil yang sudah pernah hamil dan melahirkan sebelumnya. Hal ini sesuai dengan yang diampaikan oleh Salmah (2006) yang menyatakan bahwa semakin banyak paritas semakin banyak pula pengalaman dan pengetahuannya sehingga mampu memberikan hasil yang lebih baik dan suatu pengalaman masa lalu mempengaruhi belajar.

\section{KESIMPULAN}

Kegiatan pengabdian masyarakat ini mampu meningkatkan pengetahuan responden (ibu hamil) tentang tanda bahaya kehamilan. Hal ini sesuai dengan tujuan awal dilaksanakan nya kegiatan pengabdian masyarakat ini dimana ibu hamil yang memiliki pengertahuan yang baik terhadap tanda bahaya kehamilan ini diharapkan mampu melakukan deteksi dini adanya kelainan selama masa kehamilan dan mampu menentukan tempat bersalin yang nyaman dan aman sesuai dengan harapan. Sehingga mampu mengurangi resiko peningkatan terjadinya komplikasi selama kehamilan dan proses persalinan serta menurunkan angka kematian ibu (AKI).

\section{DAFTAR PUSTAKA}

Bhutta Z.A., Soofi S., Mohammad S., Memon Z. A., Ali I., Feroze A., et al. (2011). Improvement of Perinatal and Newborn Care in Rural pakistan Thriugh Community-Based Strategies : A Cluster Randomized Effectiveness Trial. Lancet, 377(9763) : 977-988.

Departemen Kesehatan RI, 2011. Panduan Pelaksanaan Kelas Ibu Hamil. Jakarta : Depkes RI.

Meliono, Efendi. 2007. Pengetahuan Files. http://melionoetal.wordpress.

Salmah, Anditha. 2006. Paritas. http://saland.wordpress.com.2006

Soubeiga D., Gauvin L., Hatem M. A. \& Johri M. (2014). Birth Preparedness and Complication Readiness (BPCR) Interventions to Reduce Maternal and Neonatal Mortality in Developing Countries : Systematic Review and Meta Analysis. BMC Pregnancy \& Childbirth, Vol $14: 129$. 
Tinah. 2010. Pengaruh Pelaksanaan Program Kelas Ibu Hamil Terhadap Pengetahuan Dan Sikap Ibu Hamil Dalam Deteksi Dini Resiko Tinggi, (Online),

(http://jurnal.unimus.ac.id/index.php/p sn12012010 /article/view/1206/1259, diakses tanggal 12 September 2016)
United Nations fund for Population Activities, 2012. The Social Determinant of Maternal Death and Disability, (Online), (http://www.unfpa.org/sites/default/files/r esourcepdf/EN- SRH\%20fact\%20sheetPoormother.pdf, diakses tanggal 12 September 2015) 